\title{
Utilization Frequency and Distributions of Drama Language Body Standard
}

\author{
WANG Jing-dan \\ Fudan University, Shanghai,China
}

\begin{abstract}
In this paper, through the analysis of the language characteristics and the employment of the method of measurement statistics, the utilization frequency and distributions of drama language body standard are further summaried. There are rhetorical question, switching, repetition, apostrophe, etc. in the drama language body standard. Furthermore, the lower utilization frequency of the drama language body standard is revealed by comparison with the literature and art style. The figures of speech in the drama language are open and unlimited. The drama language is more emphasized on the using of the figures of speech than the colloquial style.
\end{abstract}

Keywords: drama language body, figures of speech, frequency

\section{Introduction}

Figures of speech are widely used in drama, the branch style of colloquial style and literature and art style. Meanwhile, compared with other styles, the utilization of the figures in drama takes on its own features.

On one hand, as we all know, styles have some selectivity against the figures of speech, that is to say, for certain figures, they are never used in some certain styles, while it is reasonable to be commonly used in another one or two styles. Besides, there are also a large amount of figures may be admitted by all varieties of styles, though, the utilization frequency in each style is varied. For example, the drama language body standards such as repetition, switching, apostrophe, are almost never used in official documents, political comments, scientific and technological articles. On the other hand, the styles are compatible with these figures of speech. Although the styles' selection towards figures is obvious, the cross-penetration among those styles does exist as well, especially with the continuous development and improvement of the style, this kind of compatibility is prevalent. For instance, as someone had made a point of cancelling serial verb construction, Mr. LV (1979) said in The Analysis of Some Questions in Chinese Grammar, "it looks that serial verb construction would still linger around and wouldn't go" (p. 83), the "linger around and wouldn't go" here is at first a personification in literature and art style, while now it is used and quite properly used in the scientific and technological style, which shows the compatibility of figures. Take another example, there was a paragraph in DENG's article The Speech Made When Meeting With the Committee Members of HKSAR Basic Law Drafting Committee (1993), which said:

WANG Jing-dan, Ph.D., associate professor, International Cultural Exchange School, Fudan University. 
It's gratifying to know that people adhere to the open policy of the Communist Party and Chinese government, but whenever they see wind sway the grass, whenever they see someone is against Bourgeois Liberalism, they would murmur whether there will be some changes in this society. (p. 217)

Here the "wind sways the grass" also shows the compatibility of figures. The application of metaphor and personification adds vitality and impression to official documents and technological articles and enhances the impact of those texts.

Compared with other styles, drama has its own characteristics in the use of figures, which provides an evidence for drama to be an independent branch style. As a branch style of colloquial style and literature and art style, drama shares some common features with these two styles. There are some figures commonly used both in drama and literature style, say, metaphor, parallelism, antithesis, synecdoche, quotation, pun, climax, palindrome, set-off, and anadiplosis. There are also some figures commonly used both in drama and colloquial style, such as, metaphor, switchings, repetitions, and rhetoric questions. Meanwhile, the use of metaphors in drama still has its featured and frequently used figures, for example, repetition, rhetoric questions, switching, and apostrophe.

It is of great significance for uncovering the characteristics of drama and then further deepening the research of stylistics to do intensive study on the features of figures application in drama.

\section{The Major Features of Figures Use in Drama}

Because drama is a branch style of colloquial style and literature and art style, the overall characteristics of figures' use in it is consistent with that in colloquial style and literature and art works. However, it still exists some quite unique features, which would be discussed in the following part.

\section{Relatively More Use of Figures}

Here "relatively more" has two aspects of meaning: On one hand, compared with official documents, scientific and technological articles, political comments, and their branch styles, the use of figures of speech in drama is much more. However, it is not totally absolute, especially in some certain political comments, for sometimes there are a large amount of figures existing in that kind of articles. On the other hand, within the literature and art style, the use of figures in drama is few to some degree, compared with that in prose or verse. For instance, Mr. LI (2000) has done the research and statistics in this aspect and the sum of his samples is 22,275 words, including the following works: LU Xun's work, The Native (from Complete Works of LU Xun, volumn 1) for 5,185 words; ZHAO Shu-li's work, The Floor (from Selected Works of ZHAO Shu-li) for 3,278 words; LIU Bai-yu's work, Sakura (from Selected Works of Prose edited by Department of Literature of Chinese Academy of Social Science) for 7,247 words; HE Jing-zhi's work, Ode to This Ten Years (from Collection of Odes) for 3,320 words; Scene Two of Lao She' s play, Longxu Ditch for 3,245 words (pp. 379, 382-383). The survey result is tabulated as follows in the aspect of figures of speech (see Table 1).

It is obvious to see that within the literature and art style, the order of the extent of figures' application should be verse, prose, and drama (from many to few). 
Table 1

The Use of Figures of Speech in the Literature and Art Style

\begin{tabular}{|c|c|c|c|c|c|c|c|c|}
\hline $\begin{array}{l}\text { Name of the } \\
\text { works }\end{array}$ & Metaphor & Analogy & Exaggera-tion & $\begin{array}{l}\text { Meto-nyn } \\
\mathrm{y}\end{array}$ & $\begin{array}{l}\text { Paralleli-sm } \\
\text { and ntithes-is }\end{array}$ & $\begin{array}{l}\text { Comparis-o } \\
\mathrm{n} \text { and set-off }\end{array}$ & $\begin{array}{l}\text { Rhetorical questions } \\
\text { and rhetoric questions }\end{array}$ & $\begin{array}{l}\text { Apostrophe } \\
\text { and pun }\end{array}$ \\
\hline The Native & 8 & 0 & 1 & 2 & 2 & 3 & 5 & 2 \\
\hline The Floor & 6 & 1 & 0 & 1 & 2 & 2 & 4 & 5 \\
\hline Sakura & 28 & 11 & 3 & 2 & 11 & 5 & 6 & 2 \\
\hline $\begin{array}{l}\text { Ode to this Ten } \\
\text { Years }\end{array}$ & 35 & 8 & 3 & 2 & 8 & 2 & 7 & 2 \\
\hline Longxu Ditch & 3 & 0 & 1 & 0 & 2 & 4 & 2 & 0 \\
\hline Sum & 80 & 20 & 8 & 7 & 25 & 16 & 24 & 11 \\
\hline
\end{tabular}

\section{Frequently Used Figures of Speech in Oral Expressions}

Drama is related to spoken language, which is reflected in the application of figures of speech. Such figures of speech whicn are suitable for oral expressions are often used in drama, for instance, repetition, rhetorical questions, interruption, and abrupt continuance. However, such literary figures of speech as parallelism and antithesis are less used, and broad parallelism and antithesis are applied if it is necessary, not the ones in the strict sense. It is to make the language of drama more colloquial.

\section{Its Own Features in Actual Application of Figures}

Drama has its distinct features different from other styles in terms of the use of figures, for instance, repetition. "Repetition is defined as a way of showing intense feelings by repeating the same sentences" (CHEN, 1997, p. 199). In other types of articles, repetition is generally means duplicaion of the same sentence by the writer himself. However in drama, repetition is often achieved by two people. Thus, it is called reduplication and it is used widely in drama.

\section{The Utilization Frequency and Distribution of Commonly Used Figures in Drama}

\section{The Regular Patterns of Figures Use in Drama}

In order to make clear of the utilization frequency and distribution of the drama language body standard, the researchers choose those following plays to do the study: Scene One of CAO Yu's work Thunder (1934), Scene Five of GUO Mo-ruo's work Qu Yuan (1941), Scene One of XIA Yan's work Under the Roofs of Shanghai (1937), TIAN Han’s work Plum Rains (one-act play) (1931), Scene One of WU Zu-guang's work The Hand on the Latch (year), Scene One of Lao She's work Teahouse (1956), MA Zhong-jun, JIA Hong-yuan, and ZHAI Xin-hua's work Warm Waves Outside the House (one-act play) (1980). The following table is about the use of commonly-seen figures in these plays (see Table 2).

It is shown from table 2:

(1) Frequently-used figures of speech applicable to drama.

Frequently-used drama stylistics are rhetoric questions, switchings, repetitions, and apostrophes ,which account respectively $34.30 \%$, 29.11\%, $13.30 \%$, and $4.99 \%$, reaching $81.60 \%$ in all. Resultantly, apart from the above-mentioned components, all the other figures of speech hold merely $18.40 \%$. It is concluded that the mostly applicable figures in drama are rhertoric questions, switchings, repetitions, and apostrophes. 
Table 2

The Use of Figures of Speech in the Drama Language Body

\begin{tabular}{|c|c|c|c|c|c|c|c|c|c|}
\hline $\begin{array}{l}\text { Play } \\
\text { Figures }\end{array}$ & $\begin{array}{l}\text { Thunder } \\
\text { Scene } 1\end{array}$ & $\begin{array}{l}\text { Qu Yuan } \\
\text { Scene } 5\end{array}$ & $\begin{array}{l}\text { Under the Roofs } \\
\text { of Shanghai } \\
\text { Scene } 1\end{array}$ & $\begin{array}{l}\text { Plum Rains } \\
\text { one-act play }\end{array}$ & $\begin{array}{l}\text { The Hand } \\
\text { on the Latch } \\
\text { Scene } 1\end{array}$ & $\begin{array}{l}\text { Teahouse } \\
\text { Scene } 1\end{array}$ & $\begin{array}{l}\text { Warm Waves } \\
\text { Outside the House } \\
\text { one-act play }\end{array}$ & Sum & $\begin{array}{c}\text { Percentage } \\
\text { (\%) }\end{array}$ \\
\hline Metaphor & 17 & 4 & 2 & 3 & 7 & 3 & 1 & 37 & 3.85 \\
\hline Parallelism & 0 & 32 & 3 & 2 & 3 & 2 & 8 & 50 & 5.19 \\
\hline Antithesis & 0 & 1 & 0 & 0 & 0 & 0 & 0 & 1 & 0.1 \\
\hline Metonymy & 0 & 0 & 0 & 5 & 0 & 1 & 1 & 7 & 0.73 \\
\hline Quotation & 0 & 4 & 1 & 11 & 25 & 2 & 3 & 46 & 4.78 \\
\hline Pun & 1 & 0 & 0 & 0 & 0 & 0 & 0 & 1 & 0.1 \\
\hline Climax & 2 & 1 & 0 & 2 & 0 & 0 & 2 & 7 & 0.73 \\
\hline Plalindrome & 0 & 0 & 0 & 0 & 1 & 0 & 0 & 1 & 0.1 \\
\hline Set-off & 1 & 3 & 5 & 3 & 5 & 4 & 3 & 24 & 2.49 \\
\hline Anadiplosis & 0 & 0 & 1 & 0 & 0 & 0 & 0 & 1 & 0.1 \\
\hline Repetition & 23 & 18 & 12 & 34 & 21 & 2 & 17 & 127 & 13.20 \\
\hline $\begin{array}{l}\text { Rhetorical } \\
\text { Question }\end{array}$ & 75 & 20 & 27 & 88 & 34 & 25 & 61 & 330 & 34.30 \\
\hline $\begin{array}{l}\text { Rhetoric } \\
\text { Question }\end{array}$ & 0 & 1 & 0 & 1 & 0 & 0 & 0 & 2 & 0.21 \\
\hline Switching & 49 & 9 & 88 & 32 & 48 & 9 & 45 & 280 & 29.11 \\
\hline Apostrophe & 2 & 29 & 0 & 13 & 0 & 0 & 4 & 48 & 4.99 \\
\hline Sum & 170 & 122 & 139 & 194 & 144 & 48 & 145 & 962 & 100 \\
\hline
\end{tabular}

Rhetoric questions rank first among the four figures of speech. Its status lies in that drama language should unfold the plot actively, a feature posessed exactly by rhetoric questions, which also gains the preference of playwrights. Switchings take second place on the list, because the main techniques of it, namely interruption, abrupt continuance, snap finis, are in accordance with the oral expressions, while enabling audience to understand the unspoken words of a drama and unfolding the remaining plots in an appropriate way. Repetition can help make a sketch of the character of a certain role by highlighting the state of mind of him or her in a certain situation. Overused in other types of writing, repetition always gives readers a verbose impression, while used in dialogues of dramas, the uniqueness of its advantages can not be easily substituted. Apostrophe is also used in drama, although less frequently than the other three figures of speech. Its application is always related to the content of scripts. Generally speaking, when people feel elated, passionate, depressed, or miserable, dramatists will resort to apostrophe in their dialogues to unleash their feelings. So it is used less in dramas.

(2) Figures of speech commonly used in drama but with low frequency.

Some figures of speech are less frequently used but can be spotted out in almost every drama. The tables above show that they are mainly metaphor, parallelism, quotation, and contrast. These four figures of speech are so compatible in all kinds of styles that they are common in drama. This thesis mainly focuses on the analysis of their features in application in drama.

The analysis of metaphor comes first in this section. According to our observation, metaphor is mostly found in exposition, with a small proportion in dialogue and soliloquy. In other words, dramatists often use metaphor to describe the scenes and reflect character's personality. Parallelism is the next target of analysis. Parallelism in drama is often found in monologue, especially in the emotional expressions. Moreover, broad parallelism is used 
more frequently than strict one. As for quotation, whether it is applied or not is connected with the style and habit of the dramatist. For example, the dramatist WU Zu-guang (1917-2003) preferred quotation to other figures. Most quotations in drama are well-known archaism, adages, proverbs, and so forth, such as "in the long run, whatever you're given, you pay for", “To live is better than to die”, and "One may be poor but never ceases to be ambitious". These short quotations are all suitable for oral expressions, thus commonly used in drama, while the long quotations are not. Set-off is also one of the figures of speech used commonly in drama. It is often employed to contrast two subjects, by this means, dramatists can highlight the characters' personalities and unfold the development of the plot.

(3) Figures less commonly used figures in drama.

As the table shows, these figures such as antithesis, metonymy, pun, climax, plalindrome, anadiplosis, rhetorical questions, and irony are used with low frequency. Although these figures are seldomly employed in drama, they still give unique charming and freshment to the drama. Evidently, whether these figures of speech are used or not is usually related to the playwright's writing habits and scripts' content.

\section{Horizontal Comparison Within Literature and Art Style}

This thesis would do a further analysis of differences in terms of figures applicaton in verse, prose and drama. Mr. LI has done some researches and statistics in this aspect. As what is observed from Mr. LI's work, the common feature of literature style is the frequently use of figures. The difference lies in the fact that the utilization frequency of figures in drama is lower than that in prose and verse. Besides, the figures application in verse and prose is more widely (to a certain degree, these two styles almost seldomly reject any figures), while for certain figures, they are never employed by drama.

\section{Vertical Comparison With Other Styles}

It is obvious to spot out that drama, after all, is the branch style of literature style, compared with official documents, political comments, scientific and technological article. The application of figures in drama is open and unlimited, while that in those styles like official documents, political comments, scientific, and technological articles is limited (certain figures such as metaphor, rhetoric questions, parallelism, antithesis, set-off, and climax are often used in these styles), which is the distinct feature of those styles in terms of figures. It is different for colloquial style in the aspect of figures application, for colloquial style is more random compared with drama, which is more concerned in the figures application.

This thesis above has discussed the regulations of figures application in drama and comparisons with other styles in terms of figures of speech. What's more, the use of figures in drama is still subject to the contents of scripts, playwrights' styles, and their habits. These two points should be taken into consideration on discussing this issue.

\section{Conclusions}

In conclusion, the regulations of figures application in drama and comparisons with other styles in terms of figures of speech are researched. Through the analysis of the language characteristics and the employment of the method of measurement statistics, the utilization frequency and distributions of drama language body standard are further summaried. There are rhetorical question, switching, repetition, apostrophe, etc. in the drama language body standard. Furthermore, the rules of the drama language body standard are revealed by comparison 
with the other styles. Further study of the characteristics of the drama language body standard has very important meaning to deepening the study of language body.

\section{References}

BAI, C. R. (1993). The literature rhetoric. Changchun: Jinlin Education Publishing House.

CHEN, K. (1960). The substance of the article (Volume II of The principle of the article). Shanghai: People's Literature Publishing House.

CHEN, W. D. (1997). Introduction to figures of speech. Shanghai: Shanghai Foreign Language Education Press.

DENG, X. P. (1993). Selected works of Deng Xiaoping (Vol. III). Beijing: People’s Publishing House.

LI, Y. H. (2000). Chinese stylistics. Guangzhou: Guangdong Education Publishing House.

LOU, G. L., \& ZENG, Z. G. (1987). The function of the rhetorical question (Vol. III of The rhetoric study). Shanghai: Fudan University.

LV, S. X. (1979). The analysis of some questions in Chinese grammar. Beijing: The Commercial Press.

ZHEN, Y. H. (1998). The speech style. Wuhan: Hubei Education Publishing House. 